On the other hand, the public is very much interested in the rights of a citizen, and in my humble and diffident opinion much more emphasis should have been laid on this aspect of the Act. For example, the notorious paragraph 42 , which provides the tribunal for the dismissal of " any person ... . whose continued inclusion would be prejudicial to the efficiency of the service. . .." No mention is made in this paragraph of professional efficiency or otherwise, and in its present form it provides an extremely handy weapon for political or racial tyranny of the worst order.

Is it too late for the publicity of the B.M.A. to take a slightly different line? One cannot expect doctors to know all the tricks of advertising agents, nor would one wish it ; but in the present situation the full support of the public would make all the difference between certainty of success and the possibility (almost unthinkable) of being obliged to yield to financial blackmail.

Incidentally $I$ have just returned from a lecture tour in which I spoke at the Education Offices in Ipswich. A large board in the main hall was attractively set out with anti-B.M.A. propaganda. The letterpress ended with a jubilant paragraph to the effect that doctors would be obliged to yield for financial reasons.-I am, etc.,

Scarborough.

GWENDOLINE BAKer.

\section{Branch Managers}

SIR,- So now the doctors' wives are up in arms. Rightly so. Why should they be caretakers and dustwomen for businesses (that's all they will be) belonging to the State? The doctors in Northern Ireland (though some don't know it) will cease to own their practices on and after July 5. Are these doctors going to accept service as branch managers for a multiple concern and work 24 hours daily? No other employees are asked to do it. Should we? Certainly not.-We are, etc.,

Belfast.

\section{E. J. A. Dougan.}

H. P. Lowe.

\section{Passage of Vitamin $E$ to the Human Foetus}

Sir,-In the annotation (Feb. 28, p. 400) on the passage of vitamin $E$ to the human foetus you make the following statement (now repeated so often that I suspect its elimination from textbooks will not become possible for two generations even should it be proved incorrect): "Evidence that it is required by human beings is still inconclusive. It has repeatedly been claimed that vitamin $E$ is of use in the treatment of habitual abortion, but sceptics have pointed out that abortions are often followed by full-term gestation even without special treatment."

In support of these statements you give a reference to some publications between 1933 and 1939. Surprisingly enough you make no reference at all to a more recent publication in which precisely this point was considered. In 1940 I summarized all the published records about the treatment of habitual abortion with vitamin $\mathrm{E}$ and compared, on certain assumptions which I hope were clearly stated in the paper, those figures with the expectation of full-term delivery in a habitual abortant, as shown by Malpas's previously published figures. The conclusion reached was that there was an overwhelming probability against the successful gestation in the treated patients being due to chance and not to the vitamin-E therapy.

My arguments may or may not have been sound; to the best of my knowledge they have not been criticized in the intervening eight years. Had a valid criticism been sent to you, Sir, it would presumably have been published for reasons identical with those that led you to publish my own contribution to which I have just referred (British Medical Journal, 1940, 1. 890). -I am, etc.,

Greenford, Middlesex.

\section{A. L. Bacharach.}

\section{The Posterior Pituitary and Labour}

SIR,-Dr. G. W. Harris has summarized (Feb. 21, p. 339) the evidence relating to the theory that the posterior pituitary contributes to the processes of labour. I would like to record an observation which suggests that a discharge of pituitrin-like substance occurs with each uterine contraction of labour. In 1941 a woman who had borne one child and fed him until recently from the breast was in labour with her second child.
She happened to develop a measles rash at the same time. While the rash was being looked at, beads of milk were seen to stand out on the nipples with each uterine contraction, as they do from a lactating breast during the. "draught" (a process corresponding to the letting-down of milk in cows) or after injection of pituitrin. Since the "draught" is believed to be due to secretion from the posterior pituitary, the expulsion of the drops of milk was taken as evidence that a similar secretion was occurring with, or was preceding, each uterine contraction. An injection of pituitrin at the conclusion of the second stage in this case caused the expulsion of more drops of milk.

The fact that this visible expulsion of milk during labour is exceptional-and I have not seen it since-is perhaps because the breasts rarely contain enough free-flowing secretion at term. Its rarity does not therefore necessarily rule out the tempting conclusion that labour proceeds from a series of discharges of pituitrin-like substance which acts on the prepared uterus and which is rapidly rendered inactive.

If there is indeed a fresh discharge from the pituitary evoking each contraction it is curious that an injection of commercial pituitrin given during the first stage alters the whole course of labour. Possibly the extracted active substance is more stable than the form secreted physiologically, or the crescendo of labour is produced by some cumulative action.-I am, etc.,

Esher, Surrey

Mavis Gunther.

\section{Rectal and Vaginal Temperature}

SIR,-May I offer some remarks in reply to the criticisms levelled against the use of the rectal temperature readings in the study of ovarian activity? During the past five years I have been using temperature readings whenever possible in thousands of cycles; some of the findings were published some time ago (Lancet, 1945, 2, 663). This procedure was chosen after extensive trials for several reasons.

1. Whereas it may be easier to persuade some types of patients to take an oral reading, there are an equal number who prefer to take a rectal reading as they are afraid of breaking the thermometer on the teeth. This particularly applies to hospital patients unused to employing thermometers.

2. Mouth-breathing at night, and even for a short time on waking, does lower the temperature and obscures the pattern of the temperature cycle in some women. This is not compensated, as suggested by Miss Joy L. James (Feb. 21, p. 368), by closing the mouth for five minutes before taking the reading, since this precaution delays the recording and may thereby involve a misleading reading through a rise from waking level.

3. The absolute level of the temperature is of importance, for it reflects the endocrine activity of the ovary, a matter of clinical importance quite apart from the diphasic nature of the curve.

If records by different workers are to be compared, it is essential that the discrepancies introduced by the different procedures and by the variable individual difference between rectal and oral readings should be eliminated.-I am, etc.,

London, W.1.

MARY BARTON.

\section{Scepsis Scientifica}

SIR,-It seems to me that.Prof. Geoffrey Jefferson, in his lecture "Scepsis Scientifica" (Feb. 28, p. 379), avoids the main problem in modern medicine, which is by what means and in what manner do we temper scientific thought with scepticism and at the same time avoid the paralysis of science by a completely pragmatist attitude. That the predominänt influences in present-day medicine are crude forms of empiricism, relativism, and pragmatism there can be no doubt. Scepticism has by a one-sided and false development become elevated to the role of a scientific religion. It is useful to examine the historical origins of this situation and to attempt to reveal how this "hypertrophied" development of scepticism does in fact operate as a paralysing influence in medicine.

Woodger, in his inexplicably and unwisely neglected work Biological Principles, demonstrates that the main philosophy influencing biology as a whole is that of the so-called phenomenalists, Mach, Avenarius, Pretzoldt, Karl Pearson, etc., who have revived and extended the subjective-idealist scepticism of Bacon, Locke, Hobbes, and Hume. The phenomenalists argued that as our knowledge is only relatively true, since those things which are "true" to-day are no longer true to-morrow, and as our 